\title{
Correlations between basal metabolic rate in humans with different age, gender, BMI and local earth magnetic field activity
}

\author{
Giedre Taletaviciene ${ }^{1}$, Rollin McCraty ${ }^{2}$, Naseha Wafa Qammar ${ }^{3}$, Minvydas Ragulskis ${ }^{4}$, \\ Alfonsas Vainoras ${ }^{5}$ \\ ${ }^{1}$ UPA Medical SPA, LT-66251 Druskininkai, Sveikatos 36, Lithuania \\ ${ }^{2}$ Department Research HeartMath Institute, 14700 West Park, Ave. Boulder Creek, CA 95006, USA \\ ${ }^{3,4}$ Department of Mathematical Modelling, Kaunas University of Technology, Studentu 50-146, Kaunas \\ LT-51368, Lithuania \\ ${ }^{5}$ Institute of Cardiology, Lithuanian University of Health Sciences, LT-50161 Kaunas, Sukilèlių 17, \\ Lithuania \\ ${ }^{1}$ Corresponding author \\ E-mail: ${ }^{1}$ g.taletav@gmail.com, ${ }^{2}$ rollin@ heartmath.org, ${ }^{3}$ nasehaqammar@gmail.com, \\ ${ }^{4}$ minvydas.ragulskis@ktu.lt, ${ }^{5}$ alfonsas.vainoras@lsmuni.lt
}

Received 14 November 2021; received in revised form 7 December 2021; accepted 15 December 2021 DOI https://doi.org/10.21595/chs.2021.22345

Check for updates

Copyright $\odot 2021$ Giedre Taletaviciene, et al. This is an open access article distributed under the Creative Commons Attribution License, which permits unrestricted use, distribution, and reproduction in any medium, provided the original work is properly cited.

\begin{abstract}
Daily energy expenditure includes resting metabolism (RMR), endogenous thermogenesis (or thermal effects of food), and energy expenditure associated with exercise. RMR depends on body weight, age, gender, genetic factors, medications used and health status. Every living organism is affected by external factors. Fluctuations in magnetic fields can affect almost every biological system more or less, depending on the characteristics of the particular biological system and magnetic fluctuations. Environmental energy phenomena affect psychophysical processes that can affect people in a variety of ways, depending on their sensitivity, health status, and ability to self-regulate. The aim of this study: to investigate the correlations between basal metabolic rate in humans with different age, gender, BMI and local Earth magnetic field activity. Information on gas metabolism during respiration was obtained by indirect calorimetry where the gas flow was continuously analysed. $\mathrm{O} 2$ consumption and $\mathrm{CO} 2$ emissions were continuously analysed. The best quality 5 min section was selected from the 15 min recording (automatically selected by the computer). The results were analysed and mean resting metabolic rate (M_RMR) was calculated. Investigations of metabolic rate were performed in Lithuanian, Druskininkai, Medical SPA Center „UPA”. Power of spectral density of Local Geo Magnetic field (LGMF) was calculated in 0.32 to $36 \mathrm{~Hz}$ frequency range from the Lithuanian (GCI003) magnetometer for East - West direction (E-W). 395 persons were investigated: 116 men and 279 women. All participants were divided into two groups according gender. Women and men groups were divided again into two groups according mean age, the mean was 46 years. Was analysed correlations in women younger ( $\leq 46$ years) and older ( $>46$ years) groups and the same for men younger $(\leq 46$ years) and older (> 46 years) groups. On the next step all women and all men, then younger women group, older women group, younger men group and older men group was divided according BMI mean (29), with less than $\leq 29$ BMI and with more than $>29$ BMI. On the basis of obtained results, we can conclude, that correlations between LGMF and basal metabolic rate features are negative. More expressed negative correlations are seen in persons with smaller BMI. With age negative correlations with LGMF decrease in men group and increase in women group. Sensitivity of persons of different gender to LGMF - differ.
\end{abstract}

Keywords: basal metabolic rate, local Earth magnetic field, spyroergometry, indirect calorimetry.

\section{Introduction}

The human body constantly requires energy to exist. Daily energy expenditure includes resting 
metabolism (RMR), endogenous thermogenesis (or thermal effects of food), and energy expenditure associated with exercise [1], [2]. Most physically inactive people RMR accounts for $60 \%$ and $70 \%$ of their total daily energy needs, while in physically active people it only accounts for about $50 \%$ [1]. The determination of RMR should be performed on an empty stomach, at rest, and after a period of physical and psychological relaxation [1], [2].

RMR depends on body weight, age, gender, genetic factors, and medications used [1], [2] as well as health status [3].

Energy consumption is determined by cellular mass [2], so individuals with a higher body mass index have a higher RMR than individuals with a lower BMI [4]. Studies have shown that weight loss results when there is a decrease in RMR [4]. Baseline metabolic rate (BMR), as well as RMR, is thought to decrease markedly with age. Changes in organ weight with age have a significant effect on BMR [5], and it has been hypothesized that age-related loss of muscle mass may affect energy expenditure associated with both central regulatory processes and peripheral cellular mechanisms [6].

Studies have shown that RMR changes over a lifetime. The first rapid decline in RMR occurs from birth to age 30, and the second at a much slower rate from adulthood to death. At the age of 25-30, when the human body reaches its maximum level of complexity and maturity, its RMR is $70 \%$ of its value [7]. Throughout life, women typically have a lower RMR than men. It is likely that body composition and different hormonal patterns at least partly account for such differences [7].

Studies show that people aged 40-96 who do not have a major health problem have a significantly lower RMR than those who are ill and / or functionally disabled [3]. In some diseases - COPD, diabetes, heart failure, oncological diseases - an increase in RMR is observed in their initial stage [5], [8], [9]. Additional energy is needed to neutralize chronic diseases and maintain biological homeostasis, as the body works harder to sustain biological processes and life [3], [9]. This energy demand is met by increasing the RMR at the expense of physical and cognitive energy [7]. When the metabolic reserve and body mass becomes depleted, a decrease in RMR is observed [8], physical and cognitive weakness develops, and eventually disability [7]. Thus, a high RMR can be a biological marker that provides information on the degree of instability in energy metabolism, the current use of energy reserves, and the risk of deterioration in health [3], [7].

Every living organism is affected by external factors. Fluctuations in magnetic fields can affect almost every biological system more or less, depending on the characteristics of the particular biological system and magnetic fluctuations [10]. There is a growing body of research showing that solar and geomagnetic activity affect a variety of human health and behavioral processes, with the cardiovascular and nervous systems being the most sensitive [11]. The response of the autonomic nervous system (ANS) to changes in solar and geomagnetic activity was investigated in numerous studies [11], [12]. An increase in solar wind intensity was observed to be associated with an increase in heart rate, which the researchers interpreted as a stress-specific response while increases in cosmic rays, solar radio flux, and Schumann resonance power was associated with increased HRV and parasympathetic activity [12], [13]. In another study after analyzing the data of the local magnetic field change registered by the magnetometer operating in Lithuania, the possible correlations between the time-varying intensity of the local Earth's magnetic field and the frequency of myocardial infarction were investigated [14]. The results showed that the Earth's magnetic field is related to the number of acute myocardial infarction with ST-segment elevation (STEMI) events per week and the average weekly geomagnetic field strength at different frequency ranges. Correlations varied in different age groups, as well as in men and women, which may indicate different sensitivities of the organism to the Earth's magnetic field [14]. Reviewing the literature on the health effects of geomagnetic interference, Palmer et al. suggests the following conclusions: 1) geomagnetic disturbances have a greater impact on people in higher (northern) geomagnetic latitudes; 2) abnormally high geomagnetic activity affects the health of the cardiovascular system; 3) abnormally low geomagnetic activity has a negative effect on health; 4) Disrupted geomagnetic activity has a negative impact on the health of about 10-15\% of people 
living in the study areas. 5) HRV is negatively correlated with geomagnetic interference [15], [11]. Thus, research findings support the hypothesis that environmental magnetic activity affects psychophysical processes that can affect people in a variety of ways, depending on their sensitivity, health status, and ability to self-regulate [12].

The aim of this study: to investigate the correlations between basal metabolic rate in humans with different age, gender, BMI and local Earth magnetic field activity.

\section{Methods}

\subsection{Research methodology}

Medical device used for the research: spyroergometry system Metacontrol 3000, (Cortex Biophysik $\mathrm{GmbH}$, Germany). Information on gas metabolism during respiration was obtained by indirect calorimetry where the gas flow was continuously analyzed. Metabolic costs depend on the caloric equivalents of oxygen $\left(\mathrm{O}_{2}\right)$ and carbon dioxide $\left(\mathrm{CO}_{2}\right)$ consumed, which vary according to the energy substrate (protein, carbohydrate and lipid) used [1].

The study was conducted in the morning before the participant had eaten. The participant laid on the couch for 15 minutes while psychologically and physically relaxed. Breathing was performed through a special gas flow recorder. $\mathrm{O}_{2}$ consumption and $\mathrm{CO}_{2}$ emissions were continuously analyzed and their ratio (RQ) was calculated. The best quality 5 min section was selected from a 15 min recording (automatically selected by the computer). The results were analyzed and mean resting metabolic rate (M_RMR) was calculated.

\subsection{Measure of Local Earth magnetic field}

Time varying local Earth magnetic field data were recorded at the GCI magnetometer site located in Lithuania using 2 Zonge Engineering Inc. (Tucson Arizona) ANT4 induction coil magnetometers placed in two directions - north/south and east/west. Signals from the magnetometer were collected with a 24-bit ADC (Symmetric Research, Las Vegas NV) at a sample rate of $130 \mathrm{~Hz}$ frequency. For all data the power spectral density (PSD) was calculated using a FFT (fast Fourier transformation) for every hour [16]. Power of spectral density was calculated in 0.32 to $36 \mathrm{~Hz}$ frequency range from the Lithuanian (GCI003) magnetometer for East - West direction (E-W) [17]. This frequency band embraces the same frequency bands that are typically used for human brain waves. Asses to magnetometer data (for GCI003) are in web page https://www.heartmath.org/research/global-coherence/gcms-live-data/.

\subsection{Participants}

During 2016-2020 years, 395 participants were investigated: 116 men and 279 women. For all investigated persons the mean age for men (M+/-SD) was $50.05+/-13.12$ years, for women $44.52+/-12.67$ years. The mean of body mass index (BMI) for men was $28.95+/-6.87\left[\mathrm{~kg} / \mathrm{cm}^{2}\right]$ and for women $27.05+/-5.97\left[\mathrm{~kg} / \mathrm{cm}^{2}\right]$. All investigated persons were divided into groups according age (younger $\leq 46$ years and older $>46$ years), according gender (women and men) and according body mass index BMI $(\leq 29$ and $>29)$.

Investigations of metabolic rate were performed in Lithuanian, Druskininkai, Medical SPA Center „UPA”.

The study was carried out with Kaunas Regional Biomedical Research Ethics Committee Permission No. BE-50.

\section{Results}

In article [17] we reported on the analysis of 5 years of basal metabolic rate features and LGMF changes. In this article we report on the analysis of correlations between LGMF and basal 
metabolic features: $\mathrm{M} \_\mathrm{RMR}, \mathrm{VO}_{2}, \mathrm{VCO}_{2}$ in relation to different ages, gender and BMI (body mass index - human mass divided on the height in square $\left[\mathrm{kg} / \mathrm{cm}^{2}\right]$ ). All participants were divided into two groups according gender. Than women and men groups were divided into two groups according to mean age, (mean was 46 years). We analysed correlations in younger women ( $\leq 46$ years) and older ( $>46$ years) groups and the same for younger men ( $\leq 46$ years) and older (> 46 years). We then looked at all women and all men, then the younger women group, older women group, younger men group and older men group which was divided according BMI mean (29), with less than $\leq 29$ BMI and with more than $>29$ BMI.

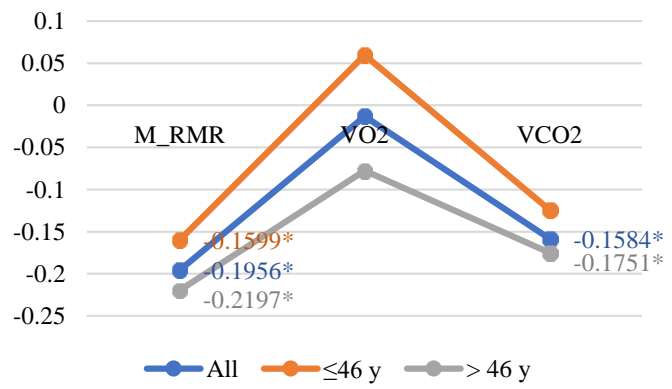

a) Women

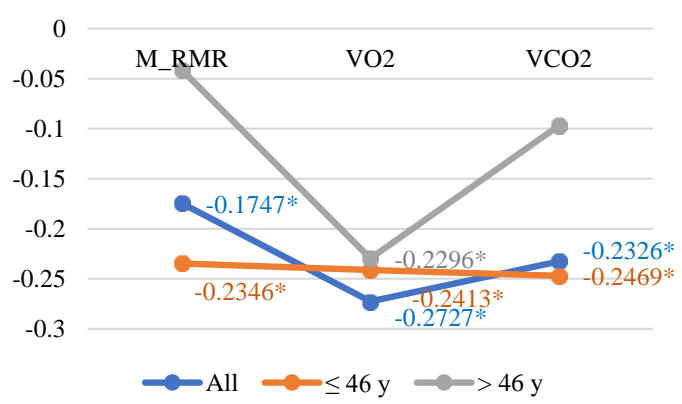

b) Men

Fig. 1. Correlations between LGMF and different age in women and men

In Fig. 1(a) and in 1(b) it is interesting to note, that with age negative correlations with LGMF in the womens group increase. In the mens group, we see decreasing of the same correlations, along with small changes with age in $\mathrm{O}_{2}$ consumption, but large changes in $\mathrm{CO}_{2}$ production and M_RMR. In the women group the changes in the negative correlations with LGMF with age are quite opposite - in the correlation of LGMF and $\mathrm{O}_{2}$ consumption, $\mathrm{CO}_{2}$ production and the increased R_BMR. More detailed correlation presentation can be found in Table 1 for women and for men. We can conclude that correlations are stronger for younger men and older women. Men have higher correlations with $\mathrm{O}_{2}$ consumption, and women with $\mathrm{CO}_{2}$ production.

Table 1. Correlations between LGMF and women/men age

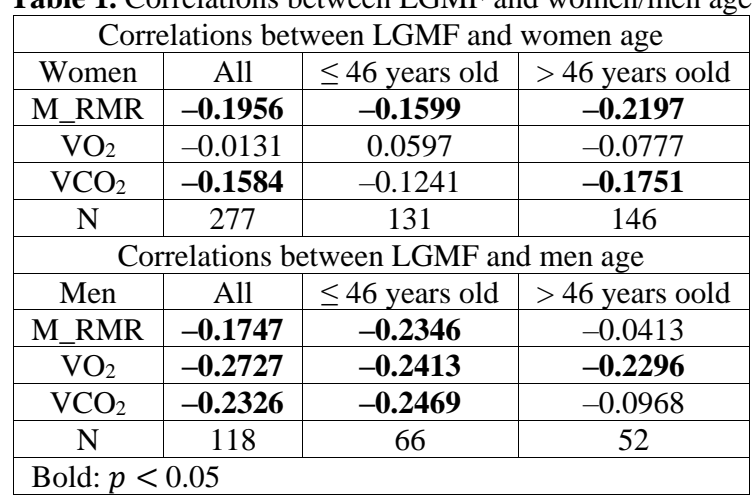

Analysis of correlations between LGMF and BMI in women and men groups show more simple changes - basal metabolic features have smaller negative correlations in persons with bigger BMI and women and men, (Fig. 2(a) and 2(b)).

Here again we can see differences between women and men in the correlations between LGMF and $\mathrm{O}_{2}$ consumption and $\mathrm{CO}_{2}$ production (Table 2). Such behaviour of those correlations in different genders is difficult to interpretate. 


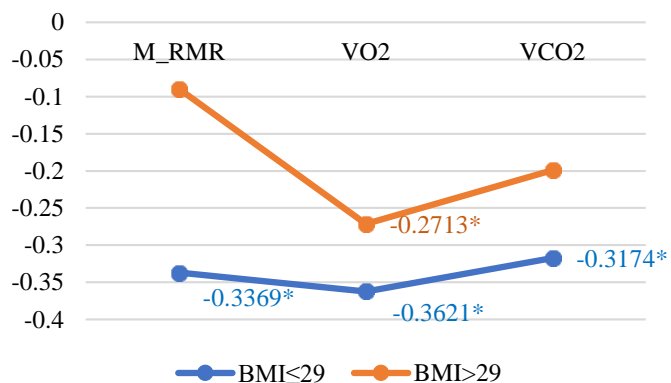

a) Men

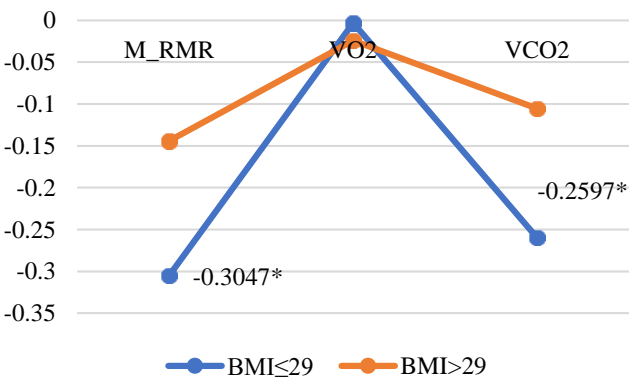

b) Women

Fig. 2. Correlations between LGMF and metabolic features in women and men with BMI less than or 29 and with BMI > 29

Table 2. Correlations between LGMF and women/men with different BMI

\begin{tabular}{|c|c|c|}
\hline \multicolumn{3}{|c|}{ Correlations between LGMF and women with different BMI } \\
\hline Women (all) & BMI $\leq 29$ & BMI $>29$ \\
\hline M_RMR & $\mathbf{- 0 . 3 0 4 7}$ & -0.144 \\
\hline $\mathrm{VO}_{2}$ & -0.003 & -0.0241 \\
\hline $\mathrm{VCO}_{2}$ & $\mathbf{- 0 . 2 5 9 7}$ & -0.1054 \\
\hline $\mathrm{N}$ & 188 & 92 \\
\hline Correlations between LGMF and men with different BMI \\
\hline Men (all) & BMI $\leq 29$ & BMI $>29$ \\
\hline $\mathrm{M} \_$RMR & $\mathbf{- 0 . 3 3 6 9}$ & -0.0898 \\
\hline $\mathrm{VO}_{2}$ & $\mathbf{- 0 . 3 6 2 1}$ & $\mathbf{- 0 . 2 7 1 3}$ \\
\hline $\mathrm{VCO}_{2}$ & $\mathbf{- 0 . 3 1 7 4}$ & -0.199 \\
\hline $\mathrm{N}$ & 67 & 50 \\
\hline Bold: $p<0.05$ & & \\
\hline \multicolumn{3}{|c}{} \\
\hline
\end{tabular}

In younger persons (Fig. 3(a) and 3(b)), we have decrease in the correlations between LGMF and basal metabolic features, except in the younger womens group in $\mathrm{O}_{2}$ consumption - where the negative correlation increases, although not significantly.

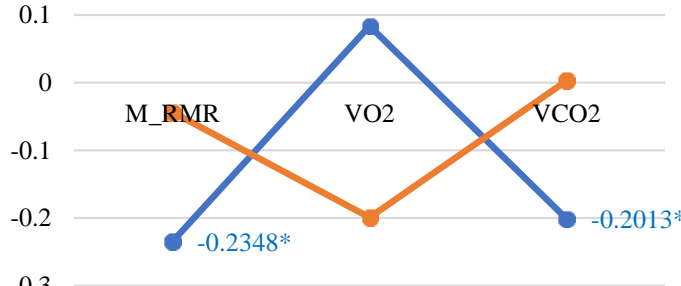

$-0.3$

a) Women

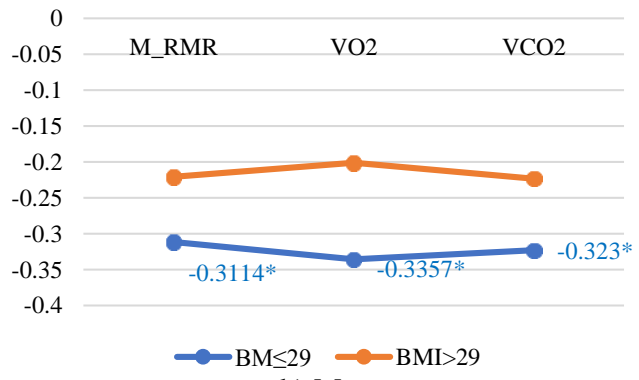

b) Men

Fig. 3. Correlations between LGMF and metabolic features in younger than 46 years women and men with BMI less than or 29 and with BMI > 29

Tables 3 show the correlations for younger persons with different BMI. The biggest correlations we found was in younger men with a BMI of less then 29.

In Fig. 4(a) and 4(b), for older persons we can see the same tendency as in young persons, the correlations between LGMF and basal metabolic rate features were slightly decreased. But again, one interesting feature - in older mens group, the $\mathrm{O}_{2}$ consumption and $\mathrm{CO}_{2}$ production was about the same as in men with a BMI $\leq 29$ and in men with a BMI $>29$, where the M_RMR became even slightly positive. Regrettably those changes where not significant due to the small number of participants. 
CORRELATIONS BETWEEN BASAL METABOLIC RATE IN HUMANS WITH DIFFERENT AGE, GENDER, BMI AND LOCAL EARTH MAGNETIC FIELD

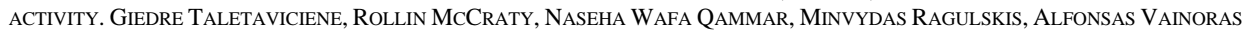

Table 3. Correlations between LGMF and women/men age $\leq 46$ year with different BMI Correlations between LGMF and women age $\leq 46$ year with different BMI

\begin{tabular}{|c|c|c|}
\hline Women (all) & BMI $\leq 29$ & BMI $>29$ \\
\hline M_RMR & $-\mathbf{0 . 2 3 4 8}$ & -0.0437 \\
\hline $\mathrm{VO}_{2}$ & 0.0839 & -0.199 \\
\hline $\mathrm{VCO}_{2}$ & $\mathbf{- 0 . 2 0 1 3}$ & 0.003 \\
\hline $\mathrm{N}$ & 109 & 21 \\
\hline Correlations between LGMF and men age $\leq 46$ year with different BMI \\
\hline Women (all) & BMI $\leq 29$ & BMI $>29$ \\
\hline M_RMR & $\mathbf{- 0 . 3 1 1 4}$ & -0.2208 \\
\hline $\mathrm{VO}_{2}$ & $\mathbf{- 0 . 3 3 5 7}$ & -0.2011 \\
\hline $\mathrm{VCO}_{2}$ & $\mathbf{- 0 . 3 2 3}$ & -0.2233 \\
\hline $\mathrm{N}$ & 45 & 21 \\
\hline Bold: $p<0.05$ & & \\
\hline
\end{tabular}

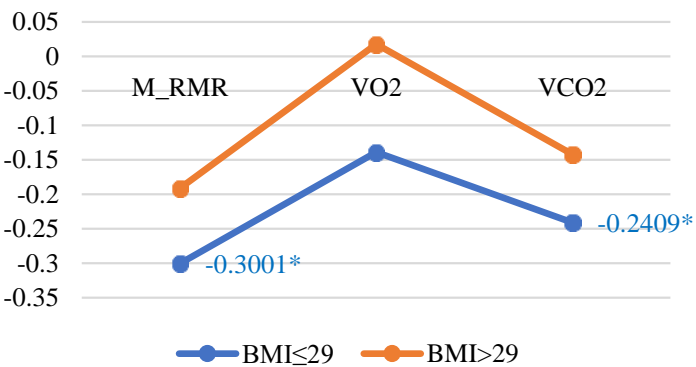

a) Women

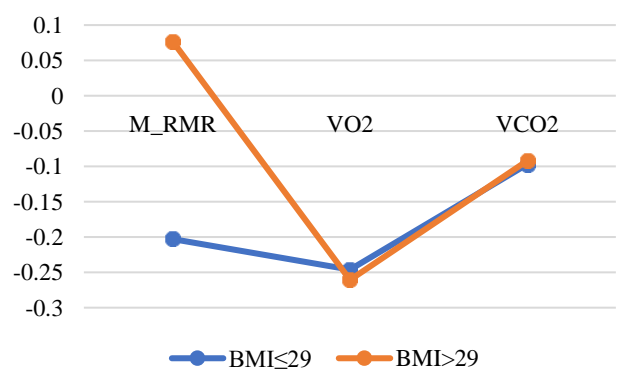

b) Men

Fig. 4. Correlations between LGMF and metabolic features in older than 46 years women and men with BMI less than or 29 and with BMI > 29

Tables 4 shown the correlations for older persons with different BMI. The biggest correlations we found was in older women with a BMI less than $\leq 29$.

Table 4. Correlations between LGMF and women/men age > 46 year with different BMI

\begin{tabular}{|c|c|c|}
\hline \multicolumn{3}{|c|}{ Correlations between LGMF and women age $>46$ year with different BMI } \\
\hline Women (all) & $\mathrm{BMI} \leq 29$ & BMI > 29 \\
\hline M_RMR & -0.300 & -0.1912 \\
\hline $\mathrm{VO}_{2}$ & -0.139 & 0.0176 \\
\hline $\mathrm{VCO}_{2}$ & -0.2409 & -0.1418 \\
\hline $\mathrm{N}$ & 77 & 72 \\
\hline \multicolumn{3}{|c|}{ Correlations between LGMF and men age $>46$ year with different BM } \\
\hline Women (all) & $\mathrm{BMI} \leq 29$ & $\mathrm{BMI}>29$ \\
\hline M_RMR & -0.2028 & 0.0769 \\
\hline $\mathrm{VO}_{2}$ & -0.2461 & -0.2606 \\
\hline $\mathrm{VCO}_{2}$ & -0.097 & -0.0917 \\
\hline $\mathrm{N}$ & 24 & 28 \\
\hline
\end{tabular}

\section{Discussion}

The results were interesting in the fact, that with few exceptions, correlations between LGMF and basal metabolic features parameters were negative, many of them significant. This means, that when LGMF activity increases, basal metabolic features parameters decrease. This suggests that when the LGMF activity, which the time varying aspects of the field, including the resonant frequencies is increased that some metabolic chains are working more effectively or coherently, and utilize energy to maintain life and healthy function. This is also supported by the fact that 
people with a smaller BMI have higher negative correlations with LGMF activity which suggest - they are more sensitive to LGMF fluctuations (Table 3 and 4). It is natural that with age and obesity such sensitivity decreases. It is also interesting that found different sensitivities in different genders, that LGMF activity impacts and activates women and mens metabolic chains differently.

\section{Conclusions}

On the basis of obtained results, we can conclude, that correlations between LGMF and basal metabolic rate features are negative. More expressed negative correlations are seen in persons with smaller BMI. With age negative correlations with LGMF decrease in men group and increase in women group. Sensitivity of persons of different gender to LGMF - differ.

\section{References}

[1] R. Blasco Redondo, "Gasto energético en reposo; métodos de evaluación y aplicaciones," Nutricion Hospitalaria, Vol. 31, No. 3, pp. 245-254, Feb. 2015, https://doi.org/10.3305/nh.2015.31.sup3.8772

[2] S. Sharma, T. Sheehy, F. Kolahdooz, and M. Barasi, Mityba. Vilnius, 2017.

[3] J. A. Schrack, N. D. Knuth, E. M. Simonsick, and L. Ferrucci, "“'IDEAL" Aging is associated with lower resting metabolic rate: the baltimore longitudinal study of aging," Journal of the American Geriatrics Society, Vol. 62, No. 4, pp. 667-672, Apr. 2014, https://doi.org/10.1111/jgs.12740

[4] C. K. Martin et al., "Effect of calorie restriction on resting metabolic rate and spontaneous physical activity," Obesity, Vol. 15, No. 12, pp. 2964-2973, Dec. 2007, https://doi.org/10.1038/oby.2007.354

[5] C. Henry, "Mechanisms of changes in basal metabolism during ageing," European Journal of Clinical Nutrition, Vol. 54, No. S3, pp. S77-S91, Jun. 2000, https://doi.org/10.1038/sj.ejcn.1601029

[6] M. R. Rizzo et al., "Resting metabolic rate and respiratory quotient in human longevity," The Journal of Clinical Endocrinology and Metabolism, Vol. 90, No. 1, pp. 409-413, Jan. 2005, https://doi.org/10.1210/jc.2004-0390

[7] C. Ruggiero and L. Ferrucci, "The endeavor of high maintenance homeostasis: resting metabolic rate and the legacy of longevity," The Journals of Gerontology Series A: Biological Sciences and Medical Sciences, Vol. 61, No. 5, pp. 466-473, May 2006, https://doi.org/10.1093/gerona/61.5.466

[8] M. Zampino, M. Alghatrif, P.-L. Kuo, E. M. Simonsick, and L. Ferrucci, "Longitudinal changes in resting metabolic rates with aging are accelerated by diseases," Nutrients, Vol. 12, No. 10, p. 3061, Oct. 2020, https://doi.org/10.3390/nu12103061

[9] S. Kim et al., "An elevation of resting metabolic rate with declining health in nonagenarians may be associated with decreased muscle mass and function in women and men, respectively," The Journals of Gerontology Series A: Biological Sciences and Medical Sciences, Vol. 69, No. 6, pp. 650-656, Jun. 2014, https://doi.org/10.1093/gerona/glt150

[10] R. McCraty, A. Deyhle, and D. Childre, "The global coherence initiative: creating a coherent planetary standing wave," Global Advances in Health and Medicine, Vol. 1, No. 1, pp. 64-77, Mar. 2012, https://doi.org/10.7453/gahmj.2012.1.1.013

[11] I. Timofejeva et al., "Identification of a group's physiological synchronization with earth's magnetic field," International Journal of Environmental Research and Public Health, Vol. 14, No. 9, p. 998, Sep. 2017, https://doi.org/10.3390/ijerph14090998

[12] A. Alabdulgader et al., "Long-Term study of heart rate variability responses to changes in the solar and geomagnetic environment," Scientific Reports, Vol. 8, No. 1, Dec. 2018, https://doi.org/10.1038/s41598-018-20932-x

[13] R. McCraty, M. Atkinson, V. Stolc, A. Alabdulgader, A. Vainoras, and M. Ragulskis, "Synchronization of human autonomic nervous system rhythms with geomagnetic activity in human subjects," International Journal of Environmental Research and Public Health, Vol. 14, No. 7, p. 770, Jul. 2017, https://doi.org/10.3390/ijerph14070770

[14] G. Jaruševičius, T. Rugelis, R. McCraty, M. Landauskas, K. Berškienė, and A. Vainoras, "Correlation between changes in local earth's magnetic field and cases of acute myocardial infarction," International Journal of Environmental Research and Public Health, Vol. 15, No. 3, p. 399, Feb. 2018, https://doi.org/10.3390/ijerph15030399 
[15] S. J. Palmer, M. J. Rycroft, and M. Cermack, "Solar and geomagnetic activity, extremely low frequency magnetic and electric fields and human health at the earth's surface," Surveys in Geophysics, Vol. 27, No. 5, pp. 557-595, Nov. 2006, https://doi.org/10.1007/s10712-006-9010-7

[16] M. Landauskas, A. Vainoras, and M. Ragulskis, "Algebraic and spectral analysis of local magnetic field intensity," Proceedings of the Lithuanian Mathematical Society Mathematic, Vol. 56, pp. 54-59, Dec. 2015, https://doi.org/10.15388/lmr.a.2015.10

[17] G. Taletaviciene, R. McCraty, V. Pestininkas, and A. Vainoras, "Investigation of parallels between human basal metabolic features and local Earth magnetic field," Journal of Complexity in Health Sciences, Vol. 4, No. 1, pp. 31-37, Jun. 2021, https://doi.org/10.21595/chs.2021.22123
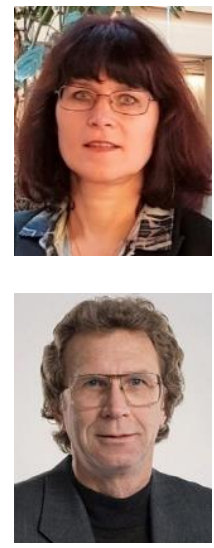
unavailable
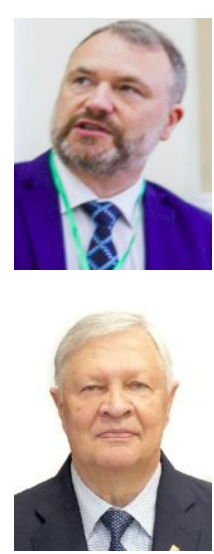

Alfonsas Vainoras received Ph.D. in biomedical sciences, medicine, in 1980. Habil. Dr. defends on 1996. Now is working in Institute of Cardiology, Lithuanian University of Health Sciences. Is working on ECG nonlinear analysis and is studying local magnetic field and human health interactions. In this work he was responsible for conceptualization, data curation, formal analysis, methodology, project administration, resources, software, supervision, validation, visualization, writing - original draft preparation, writing - review and editing.

Giedrè Taletavičienė, Ph.D., doctor, Upa Medical SPA, Druskininkai. Doctoral Dissertation „Changes of electrocardiographic parameters and their concatenations during whole-body cryotherapy and peloidotherapy procedures" 2014 y. in Lithuanian University of Health Sciences. Is working on curortology and recreation medicine, on ECG nonlinear analysis and is studying local magnetic field and human health interactions. In this work she was responsible for conceptualization, investigation, methodology, supervision, validation, writing - original draft preparation.

Rollin McCraty, Ph.D., Executive Vice President and Director of Research. Rollin McCraty of Boulder Creek, Calif., is executive vice president and director of research of HeartMath Institute. McCraty is director of research and project coordinator of the Global Coherence Monitoring System. He has been with HeartMath since its creation in 1991. He is a psychophysiologist and a professor at Florida Atlantic University. McCraty's research interests include the physiology of emotion, with a focus on the mechanisms by which emotions influence cognitive processes, behavior and health. He and his team regularly participate in studies with scientific, medical and educational institutions worldwide. McCraty has written extensively and been widely published in his areas of scientific interest. He holds numerous memberships, including with the American Autonomic Society, Pavlovian Society, National Association for Psychological Science, Association for Applied Psychophysiology and Biofeedback and Society for Scientific Exploration. In this work he was responsible for conceptualization, data curation, project administration, supervision, validation, writing - original draft preparation, writing - review and editing.

Naseha Wafa Qammar obtained her bachelor's degree in electrical engineering from University of Engineering and Technology, Peshawar-Pakistan. Sustainability and Energy Management were the focus of her postgraduate studies. Her research training for her master's degree was conducted at Arizona State University, USA. Her current research focuses on nonlinear time series analysis. In this work she was responsible for formal analysis, visualization.

Minvydas Ragulskis received the Ph.D. degree from Kaunas University of Technology in 1992. He studied applied mathematics at Kaunas University of Technology from 1984 to 1989. He has been a Professor of applied mathematics with the Kaunas University of Technology since 2002. His current research interests include nonlinear dynamics, time series analysis, and applications of mathematics in biomedicine. In this work he was responsible for conceptualization, data curation, writing - review and editing 